\title{
A Linguistic Image and a New Semantic Triangle
}

\author{
Innes Merabishvili \\ Ivane Javakhishvili Tbilisi State University, Tbilisi, Georgia
}

\begin{abstract}
The present article aims to suggest novelty in the theory of the meaning of a word. Traditionally, the study of the meaning of a word is the study of correlation between the three points of a semantic triangle: nomination, concept, and referent. No doubt, that a word with its meaning is a linguistic phenomenon. As for a referent, it is always extralinguistic. The question is: How does a referent, as an object of extralinguistic reality, participate in the formation of the meaning? The article argues that extralinguistic reality is reflected in the form of a sensuous imprint but developed into a sensuous image in the process of formation of a word as a second signal system (Pavlov's theory on two signal systems). The author regards a sensuous image existing in a word as a linguistic image. The acknowledgment of a linguistic image in a word permits us to present the meaning of a word as a correlation of three main components: nomination, significatum, and linguistic image.
\end{abstract}

Keywords: semantic triangle, referent, linguistic image

\section{Introduction}

The aim of the article is to reveal and present a linguistic image against the background of the meaning of a word as based on the most popular and essential attitude towards the problem.

The meaning of a word has been widely discussed by many academic fields but it has been an object of profound studies especially for linguistics and claims for further development in accordance with current attitudes towards the process of reasoning and consciousness.

\section{Traditional Semantic Triangle}

In connection with the problem of the meaning of a word, I offer to consider a traditional and famous semantic triangle suggested by C. K. Ogden and I. A. Richards in their book The Meaning of Meaning, first published in 1923 (Ogden \& Richards, 1923). According to it, the meaning of a word is represented as a correlation between nomination, as the sound form of a word, significatum, as a concept, and referent as an object of the real world (see Figure 1). All the debates to study the meaning of a word, which span almost a hundred years, are numerous attempts to define these three points and the correlation between them as in language as a system as well as in speech. Ferdinand De Saussure's dichotomy (De Saussure, 1977) is exceptionally important for the studies.

Innes Merabishvili, professor, Ph.D., Head of the Chair of Translatology at the Faculty of Humanities, Ivane Javakhishvili Tbilisi State University, Tbilisi, Georgia. 


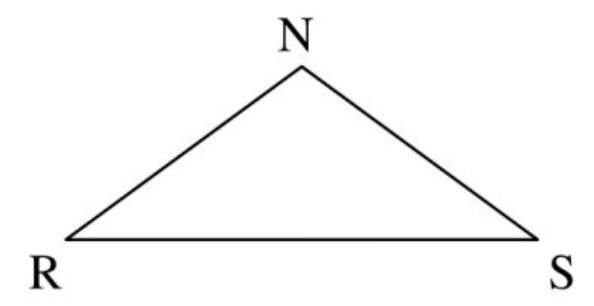

Figure 1. Semantic triangle by Ogden and Richards.

It should be noted that in the second half of the 20th century alongside with deep, thorough, and scrupulous studies of the word meaning, linguists appeared to be carried away by perspectives of a new and systematic approach which regards a text as a whole and is known as text linguistics. Though this new branch of linguistics succeeded in revealing new dimensions and categories of a text as a whole, it never declared the word as the main unit of a text that, in my opinion, created a serious gap in the studies devoted to the meaning of a word. The frame of one article never permits to present a broad observation on the subject (Merabishvili, 2005) and therefore I will focus attention on the above presented semantic triangle and a referent as one of its points in order to present a new model of the meaning of a word.

I argue that a word with its meaning is a linguistic phenomenon but a referent as an object of reality is always extralinguistic. The question is: How does a referent as an extralinguistic phenomenon participate in the formation of the meaning when we are aware of the fact that any word of a language as a system is a reflection of extralinguistic reality that is implied in its meaning but in active speech, be it oral or written, a word with its nomination and concept refers to a concrete object of reality?

In current linguistics, the most popular term for a referent is a denotatum. Due to the dichotomy of language, I offer to distinguish two types of denotatums: a general denotatum, implying a class of objects a certain word stands for in a language as a system, and a concrete denotatum, implying a concrete object of reality the word refers to in speech. These two denotatums could be indicated by the following two signs accordingly: $D$ and $D_{l}$.

When a word is used in its usual meaning, the concrete denotatum represents the whole class of objects that is implied under the word in language as a system. This could be indicated in the following way: $\mathrm{D} \approx \mathrm{D}_{1}$. E.g., if we say "the book is on the table and you can read the story in it", i.e., the concrete denotatum of the word "book" is one of the classes of books the word implies. In such cases, significatum reflects denotatum, almost equally corresponding to it: $\mathrm{S} \approx \mathrm{D}$.

When occasional meaning is developed, we observe that these two denotatums are not of equal qualities. A word reflecting a certain class of real objects can signify in speech an object of reality that is not implied by that class of objects the word stands for in a language: $\mathrm{D} \approx \mathrm{D}_{1}$. Therefore in such cases, significatum or a word does not equally correspond to a concrete denotatum: $S \approx \mathrm{D}_{1}$. Before illustrating this phenomenon by an example, I have to note that the imbalance between two kinds of denotatums results in great changes in the concept of a word, i.e., in its significatum, that could be proved by componential analysis.

\section{Componential Analysis of a Word}

The popular method of componential analysis permitted linguists to decompose a significatum of a word into semas, i.e., minimal units of meaning that have different semantic weight. Decomposition of the meaning 
of a word into semas goes back to Michael Breal and his famous book "Essai de semantique" (Breal, 1883). Linguists realized the perspective of uncovering the mechanism of word relations in speech that seemed very obscure before.

Nowadays we may compare this process with the decomposition of an atomic nucleus, especially when it encourages new waves of research.

Semas of maximum weight create the kernel of the meaning. The other semas are of less weight and surround the kernel as secondary features. Graphically, it can be presented in the following way (see Figure 2):

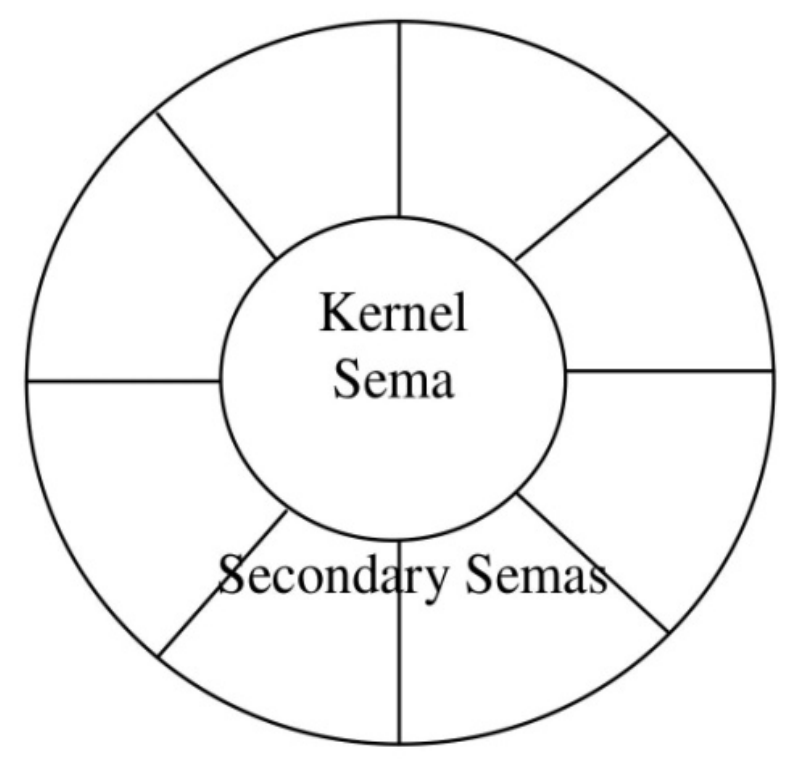

Figure 2. Kernel structure of a word.

If a word is used in occasional meaning, we observe decomposition of the meaning, actually of its concept, into different semas, where under the influence of context they are newly rearranged creating a new kernel surrounded by new secondary semas.

Describing the struggle of dawn with night, an American poetess Amy Lowell (1874-1925) attributed "the sun" with an unusual word "tiger", thus creating an occasional word-combination "the tiger sun":

\author{
Night Clouds ${ }^{l}$ \\ The white mares of the moon \\ rush along the sky \\ Beating their golden hoofs \\ upon the glass Heavens; \\ The white mares of the moon are all standing \\ on their hind legs \\ Pawing at the green porcelain doors \\ of the remote Heavens. \\ Fly, mares! \\ Strain your utmost,
}

${ }^{1}$ Lowell, 1925, p. 222. 


\section{Scatter the milky dust of stars, \\ Or the tiger sun will leap upon you \\ and destroy you \\ With one lick of his vermillion tongue}

From the point of view of language as a system, the noun "sun" comprises the leading lexical sema "the luminous celestial body, around which the earth and other planets revolve, from which they receive heat and light" ${ }^{\prime 2}$. This sema can be presented as a kernel sema that is surrounded by a number of different secondary semas, such as, e. g., of colour: "golden", "yellow", "red", etc., of time: "winter", "spring", "summer", "autumn", or "dawn", "morning", "afternoon", "evening", etc. Among the secondary semas of the word, we may also distinguish such semas as "bright", "powerful", "destructive", "active”, etc. (see Figure 3).

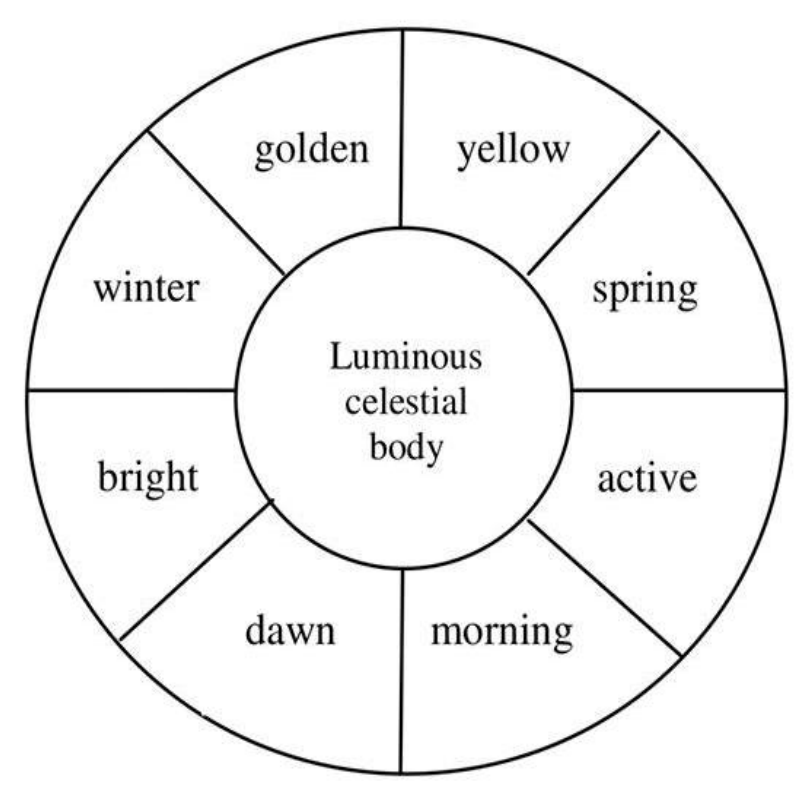

Figure 3. Kernel structure of the word "sun".

The presence of secondary semas certainly implies the increase of their relevance in active speech and leads to their transformation from the surrounding into the kernel of the lexical meaning. In usual word-combinations, the noun "sun" can be attributed by a number of words, the lexical meanings of which correspond to the aforementioned secondary semas such as "golden", "hot", "warm", "strong", "powerful", "destructive", "active", etc. Secondary semas, which may become relevant in speech, enlarge the kernel of the lexical meaning, but the latter appears to be more concrete and precise, e.g., "hot summer sun", "cold winter sun", etc. This is the way in which usual word-combinations are created and realized in speech.

In contrast to the aforementioned, in "the tiger sun", we have an occasional combination of words. It is clear, that in the poem "Night Clouds", the poetess strives to express the destructive power of the rising sun towards the night clouds, trying at the same time to depict the colourful scene of that mysterious change in nature. And this is done artistically in the most unexpected way (that is characteristic for poetry) by choosing the word "tiger" as an attribute to "the sun".

\footnotetext{
${ }^{2}$ Here and after the definitions of words are based on the following dictionary: The Universal Dictionary of the English Language Edited by Henry Cecil Wild, RKP, Toppan, London, 1982.
} 
What is the basis for their connection? The significatum of "tiger" comprises a whole number of qualities characteristic for the rising sun, but in a very compact, laconic, and artistic way. Unexpected contrast adds to the impressive power of a newly created word-combination. From the point of view of language as a system, the lexical meaning of the noun "tiger" comprises the following kernel sema: "a large Asiatic carnivorous mammal of the cat family having a tawny coat transversely striped with black". The kernel of the meaning is surrounded by a number of secondary semas, such as "wild", "fierce", "active", "destructive", etc. (see Figure 4). In the word-combination "the tiger sun", the noun "tiger" does not designate an animal, but is meant to designate certain characteristic features of the sun such as "strong", "active", "destructive", etc. These semas appear to be common both for "tiger" and "the sun" that leads to their actualization in the kernels of the meanings of these words.

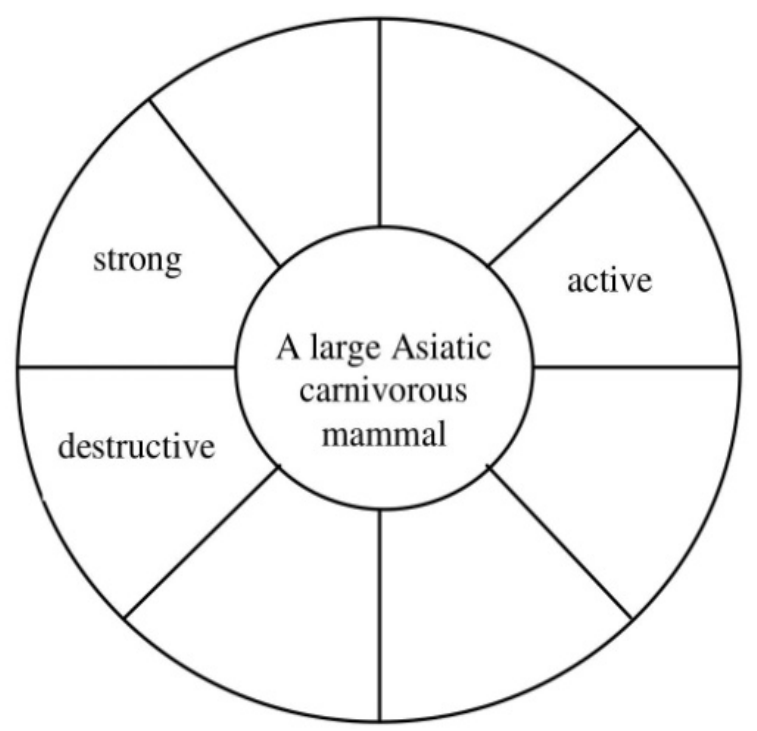

Figure 4. Kernel structure of the word "tiger".

Due to the change of the meaning of "tiger", we observe changes in its significatum, namely when its kernel sema is substituted by secondary semas creating a new kernel of a newly formed meaning.

But what happens to the former kernel sema of "a large Asiatic carnivorous mammal of the cat family"? An imaginary presence of a tiger as of an animal is easily proved by the further development of metaphors: "the tiger sun will leap upon you" and "with one lick of his vermillion tongue". "Vermillion tongue", on the one hand, adds to the image of the animal, but on the other hand, to the colour of the rising sun.

The question is: What happens to the meaning of a word when its usage is occasional? In order to answer the question, I applied to fundamental findings of human physiology.

\section{A Word as a Second Signal System}

According to I. P. Pavlov's theory on two signal systems (Pavlov, 1949, p. 163; Pavlov, 1940-1949), a word represents a second signal system that has great power of generalisation and abstraction. The first signal system implies all that we have in the form of impressions, feelings, and ideas that we receive from the outer world besides the words that we hear or see. 
A word as the second signal system represents a signal of the first signal system, as "the signal's signal", which forms our additional and particularly human advanced reasoning. Due to the latter or the second signal system, a human being differs from an animal. The first and second signal systems are indivisible and the excitation of the first signal system, which is caused by signals of objects and phenomena of the outer world, passes on to the second signal system. Knowing this, I put further questions for discussion:

(1) What kind of changes do we observe when the first signal system is transformed into a word?

(2) Is a word the result of abstract reasoning only, the final product of which is a concept?

(3) Can our knowledge on an object or phenomenon, as that reflected in a word, be equated to the concept of that word?

Human consciousness exists beyond the concept of a word and makes a word concretely real and emotionally charged in certain instances of speech. Pavlov was certainly bound to acknowledge the sensuous aspect of a word when noting: "If you want to use a word, every time imply the reality beyond the word" (Pavlov, 1949, p. 163).

Can a word in speech realize any kind of relation with sensuous impressions? The latter implies the imprints of audio, visual, or other kinaesthetic impressions that each person receives from the outer world during the process of sensuous cognition of the world. As observed, an imprint of sensuous impressions is constantly present in each word as a kind of standard. Otherwise we would never control what kind of reality could be meant by the use of this or that word that is unimaginable from the point of view of language as a social phenomenon. Objective nature of that sensuous imprint in each word certainly implies the presence of a subjective factor that, as a result of individual perception, is permanently characteristic for the author of the speech, on the one hand, and its receiver (receptor), on the other.

In human speech, in contrast to animals, an "imprint" belongs to the first signal system and takes part in the formation of a word as a second signal system. For living systems of high organization, the meaning of a signal usually exists in the form of an ideal image, by means of which only the reflected object is presented as a real one.

In gnoseology, image is a fundamental category and is used in connection with sensuous reflection and abstract thinking as well. Sensuous and conceptual images differ according to the level of reflection-sensuous or conceptual.

The presence of a conceptual image in a word is beyond doubt. As for a sensuous image in a word, it is obvious, that its presence is felt, but intuitively only. The fact, that Ogden and Richards placed a referent in the semantic triangle, as its constituent part, confirms the aforementioned and therefore calls for its acknowledgement.

\section{A linguistic Image and a New Semantic Triangle}

The above presented sensuous image existing in a word I offer to regard as a linguistic image.

The co-existence of a linguistic image and a significatum as a conceptual image within the limits of one word is a precondition of creating a word as a linguistic, social, and psychological phenomenon.

Linguistic image and significatum (concept) are always dialectically connected with each other in as far as they represent the results of reflecting one and the same object of reality within one word.

The acknowledgment of a linguistic image in a word permits us to present the meaning of a word as a correlation of three main components: 
(1) Nomination, as a sound form of a word;

(2) Significatum, as a concept;

(3) Sensuous image, as a linguistic image.

Graphically, this correlation can be also presented in the form of a triangle, where "I"-indicates "image", "N"-_"nomination", and "S"-_"significatum" (see Figure 5).

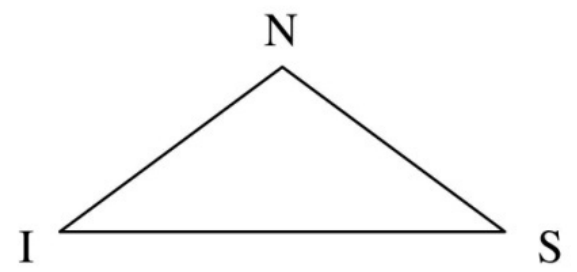

Figure 5. Semantic triangle offered by Innes Merabishvili.

A further study of the points of the presented triangle permits to say that specific weight of each unit depends upon the usage of a word. In neutral speech, significatum is the leader, but it may enlarge its informative capacity in artistic speech (text). In artistic speech, nomination may acquire additional emphasis due to alliteration, sound symbolism, etc., when in special cases, nomination becomes the leader. In artistic texts, especially when the words develop figural meanings, informative capacity of a linguistic image is enlarged and it becomes the leader. In ordinary speech, its presence is imperceptible and unostentatious.

In language as a system, a linguistic image is, as if in deep slumber, on the very bottom of the word meaning, but is reincarnated in the hands of a wordsmith. No wonder Bodler called poetry "a magic spell" (Jakobson, 1987, p. 85) and A. Losev spoke about the magic nature of a word in his "Philosophy of Name" (Losev, 1993, p. 627).

The article argues that magic power of a word, its being an inexhaustible source of influence and flexible informative capacity, is due to the existence of a linguistic image enclosed in every word of a language as a system.

It is a word with its three points that reflects general denotatum (D), but in speech (text), it refers to a concrete denotatum $\left(D_{1}\right)$, as a referent, that is an object of extralinguistic reality. Graphically, this could be presented in the following form (see Figure 6):

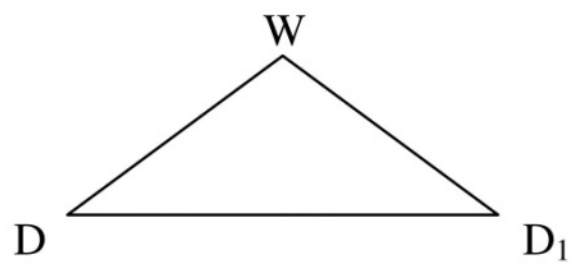

Figure 6. A semantic triangle of the word's connection with extralinguistic reality.

\section{Conclusion}

In current linguistics, the understanding of the meaning of a word is based on a traditional and famous semantic triangle suggested by Ogden and Richards. The new approach towards the study of the meaning of a word from the point of view of linguistics, gnoseology, and physiology has revealed the fact that the meaning of any word is the correlation of nomination, concept, and linguistic image. 
Linguistic image, as one of the components of the meaning of a word, when accentuated, creates an artistic effect thus determining creative power of a whole text.

The above presented model of the meaning of a word, besides its theoretical significance, proves to be a trustworthy basis especially for lexicography, text linguistics, and translating activities.

\section{References}

Breal, M. (1883). Essai de semantique (Semantic testing). Paris: Librarie Hachette Et C.

De Saussure, F. (1977). Course in general linguistics. In C. Bally and A. Sechehaye, Eds.; W. Baskin, Trans, With the collaboration of A. Riedlinger, Lausanne and Paris: Payot. Glasgow: Fontana/Collins.

Jakobson, R. (1987). Works on poetics. Moscow: Progress (in the Russian language: Якобсон, Р. (1987). Работы по поэтике. Москва: Прогресс).

Losev, A. F. (1993). Entity, name, cosmos. Moscow: Misl (in the Russian language: Лосев, А. Ф. (1993). Бытие, Имя, Космос. Москва: Мысль).

Lowell, A. (1925). What's O'clock. Boston: Houghton Mifflin Company.

Merabishvili, I. (2005). Linguistics of poetic translation (in the Georgian language with an English summary). Tbilisi: The Byron Society of Georgia.

Ogden, C. K., \& Richards, I. A. (1923). The meaning of meaning. London: Routledge \& Kegan Paul Ltd.

Pavlov, I. P. (1940-1949). Complete works in five volumes. Moscow-Leningrad: Academy of Sciences of the USSR (in the Russian language: Павлов, И. П. (1940-1949). Полное собрание трудов. т. 1-5. Москва-Ленинград: Акад. Наук СССР).

Pavlov, I. P. (1949). Pavlov's Wednesdays (Vol. 3). Moscow-Leningrad: Academy of Sciences of the USSR (in the Russian language: Павлов, И. П. (1949). Павловские среды. т. 3. Москва-Ленинград: Акад. Наук СССР).

Wild, H. C. (1982). The universal dictionary of the English language. London: RKP, Toppan. 